\title{
The Impacts of Company Size on Leadership
}

\author{
Thomas George Marx ${ }^{1, *}$ \\ ${ }^{1}$ College of Management, Lawrence Technological University, USA \\ *Correspondence: College of Management, Lawrence Technological University, USA. E-mail: tmarx@ltu.edu
}

Received: January 10, 2017

Accepted: January 18, 2017 Online Published: January 25, 2017

doi:10.5430/mos.v4n1p82

URL: http://dx.doi.org/10.5430/mos.v4n1p82

\begin{abstract}
This paper empirically tests the impacts of company size, measured by total sales revenues, on the importance of 12 essential leadership functions, (e.g., encouraging teamwork), six skills (e.g., interpersonal), seven traits (e.g., being decisive), four leadership styles - participatory, directive, tasks oriented, and employee oriented, and on leadership effectiveness.

The findings evidence patterns of leadership at larger companies that are significantly different from smaller companies. The collective findings make a compelling argument that increasing company size reduces the importance of leaders engaging and interacting with followers. This likely reflects characteristics of larger companies that lessen the importance of or substitute for employee engagement and interpersonal interactions. However, the leadership at larger companies was not found to be less or more effective. The study also found that larger companies are more risk averse, which has additional implications for leadership. The findings have a number of implications for practitioners, researchers, and faculty teaching leadership.
\end{abstract}

Keywords: company size; leadership; strategy; organizational structure; leadership styles

\section{Introduction}

Contingency models of leadership were introduced in the 1960s (Fiedler, 1967; Korman, 1966) in reaction to the failures of earlier trait and behavior models to identify universal requirements for effective leadership. These models focus on the impacts of internal organizational goals, systems, and processes (Kerr, 1985; Miner, 1982); the nature of the tasks to be performed (House, 1996; Vroom \& Yetton, 1974); the maturity, knowledge, skills, and experience of followers (Blake \& Mouton, 1964; Hersey \& Blanchard, 1977, 1969); leader-follower relationships (Fiedler, 1967); and the impacts of the organization's strategy on leadership (Marx, 2015).

The effects of company size on leadership through impacts on formal hierarchical structures, standardized systems, constraints on decision making, and wider spans of control are often noted in the literature (Bass, 2008), however recent empirical research that tests the impacts of company size on leadership is limited, and provides mixed, often contradictory, results. Bass (1960) found that increasing size encourages task-oriented leadership; Blankenship and Miles (1968) and Wofford (1971) that it increases the importance of participatory leadership. Erez and Rim (1982) found that leaders in larger organizations exhibit greater participatory and less directive leadership; Vienneau (1982), employing the LBDQ, found that both consideration (task oriented) and initiation (employee oriented) leadership are greater in larger organizations, and, completing the loop, Sheridan and Vredenburgh (1979) found size has no effect on leadership behavior.

While the effects of company size on leadership are often noted and frequently studied, empirical research is limited, and results inconclusive. The purpose of this paper is to provide much needed empirical evidence of the effects of company size on leadership by assessing the effects of company size, measured by total sales revenues, on four fundamental dimensions of leadership and its effectiveness as shown in Figure 1. The findings have a number of important implications for business practitioners, researchers, and faculty teaching leadership and management. 


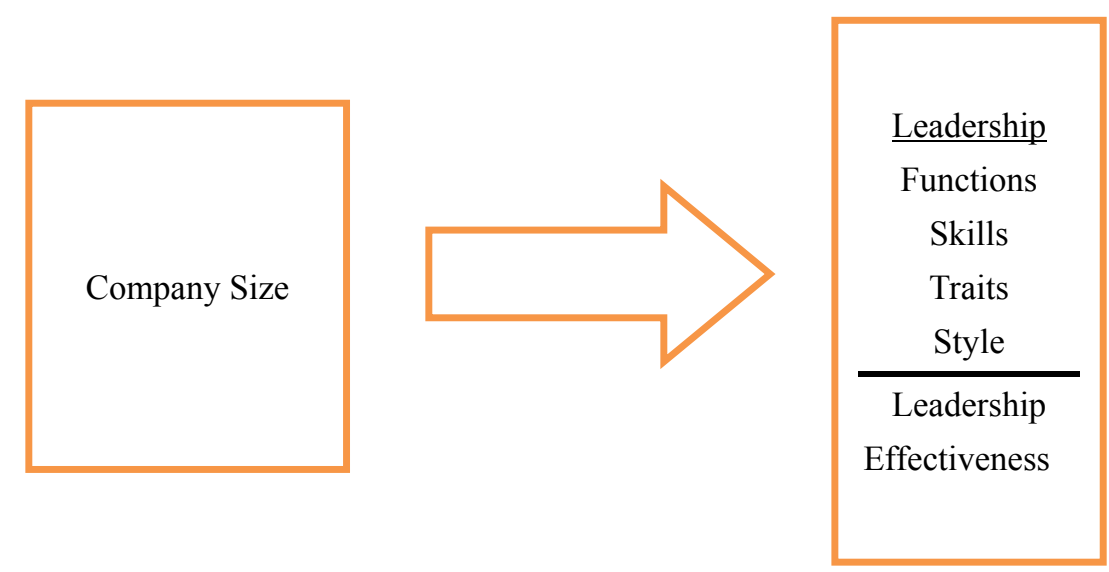

Figure 1. The Impacts of Company Size on Leadership and its Effectiveness

This paper tests the impacts of company size on the importance of essential leadership functions, skills, traits, and styles identified in the literature, and on leadership effectiveness. The 12 leadership functions include creating a shared organizational vision, promoting quality, productivity, innovation, and effective supplier relationships; obtaining people with needed skills, encouraging teamwork and empowering followers; increasing the organization's competitive advantages; ensuring budget and profit goals are met; and being a change agent (Kotter, 1990; Northouse, 2014; Yukl, 2006). The six skills required for effective leadership include technical, administrative, analytical, interpersonal, communications, and strategic planning (Munford, et al., 2000; Northouse, 2014). The seven essential leadership traits included in the study are being decisive, persistent, confident, sociable, adaptable, open minded, and willing to take risks (Hughes, et al., 2009; Kirkpatrick \& Locke, 1991; Kouzes \& Posner, 2007; Zaccaro, 2007).

Participatory, directive, tasks oriented, and employee oriented (Bowers \& Seashore, 1966; Daft, 2011; Hemphill \& Coons, 1957) are the four basic leadership styles included in the study. Participatory and directive leadership are treated as opposite ends of a single continuum - leaders who are more participatory are less directive (Tannenbaum \& Schmidt, 1958). Employee and task-oriented leadership are treated as independent variables (Hemphill a\& Coons, 1957), which enables leaders to be both employee and task oriented. The leadership styles are constructs measured by behaviors critical to each style as shown in Table 1. Leadership effectiveness is assessed on a 5-point Likert scale from limited to extremely effective.

The reliability of the leadership style constructs was tested using Cronbach's alpha (Cronbach, 1951). Cicchetti and Sparrow (1990) suggest the following reliability (r) guidelines for significance: $\mathrm{r}<.70$ (unacceptable), $.70 \leq \mathrm{r}<.80$ (fair), $.80 \leq \mathrm{r}<.90$ (good), and $\mathrm{r} \geq .90$ (excellent). Adjusted reliability scores using the Spearman-Brown prophesy formula $\left(\rho_{x x^{\prime}}^{*}=\frac{2 \rho_{x x^{\prime}}}{1+\rho_{x x^{\prime}}}\right.$ where $\rho_{x x^{\prime}}^{*}=$ corrected reliability and $\rho_{x x^{\prime}}=$ current reliability) are also calculated in

Table 1 because there are less than five measures of each leadership style construct. The adjusted alpha scores for all constructs are well above .8 , indicating good to excellent reliability. 
Table 1. Reliability of Leadership Styles

\begin{tabular}{lllll}
\hline Leadership Style & Mean & SD & alpha & corrected \\
\hline & & & & \\
Participatory & & & 0.8387 & 0.91 \\
$\quad$ Encourage followers to make suggestions for improvement & 3.644 & 1.099 & & \\
$\quad$ Consult with followers when facing a problem & 3.542 & 1.116 & & \\
Task Oriented & & & 0.7274 & 0.842 \\
$\quad$ Give followers specific tasks to perform & 3.259 & .088 & & \\
$\quad$ Give followers specific goals to accomplish & 3.648 & 1.029 & & \\
$\quad$ Give followers detailed instructions for each task & 2.511 & 1.260 & & \multirow{2}{*}{0.803} \\
Employee Oriented & & & 0.8066 & 0.893 \\
$\quad$ Get to know followers individually & 3.308 & 1.152 & & \\
$\quad$ Show concern for followers' job satisfaction & 3.597 & 1.063 & & \\
$\quad$ Encourage followers to work together & 3.729 & 1.096 & & \\
\hline
\end{tabular}

\section{Methods}

The survey instrument, developed specifically for this study, was directed to executives with professional leadership experience at for-profit companies in the manufacturing sector. The respondents represent various levels of leadership within their organizations, up to and including CEOs. Social bias was minimized by ensuring anonymity and confidentiality of both respondents and their organizations, and providing no compensation for participating. Over 600 responses to the questionnaire were received; 452 included responses to all the analytical questions and were included in the analyses. Some responses included in the study did not provide data for all three profile questions in Tables 2-4.

The sample provides good representation of companies of different sizes (measured by total sales revenues) with each size category accounting for over $13 \%$ of the sample. However, the sample tended towards larger organizations, with two-thirds of the companies having sales over $\$ 10$ million, and over $40 \%$ having sales over $\$ 100$ million.

Table 2. Size of Organizations

\begin{tabular}{lll}
\hline Size of Organization & Count & Percent \\
\hline Less than 10 million & 138 & 33.82 \\
11 to 100 million & 99 & 24.26 \\
101 million to 1 billion & 60 & 14.71 \\
1.1 billion to 10 billion & 55 & 13.48 \\
Over 10 billion & 56 & 13.73 \\
\hline $\mathrm{N}=408$ & &
\end{tabular}

The participants have significant leadership responsibilities measured by the number of people they lead that ranges from under $10(35 \%)$ to over $100(16 \%)$, with nearly two-thirds of the leaders having over 10 followers, and $30 \%$ over 50.

Table 3. Number of Followers

\begin{tabular}{lll}
\hline People Led & Count & Percent \\
\hline$<10$ & 113 & 34.77 \\
$11-25$ & 73 & 22.46 \\
$26-50$ & 42 & 12.92 \\
$51-100$ & 46 & 14.15 \\
$>100$ & 51 & 15.69 \\
\hline $\mathrm{N}=325$ & &
\end{tabular}

The leaders in the study also have extensive leadership experience. Over $85 \%$ of the leaders have five or more years of leadership experience; nearly two-thirds over 10 years; and $40 \%$ over 20 years of experience as business leaders. 
Table 4. Total Years of Leadership Experience

\begin{tabular}{lll}
\hline Years Leadership & Count & Percent \\
\hline$<5$ & 48 & 13.83 \\
$5-10$ & 61 & 17.58 \\
$11-20$ & 98 & 28.24 \\
$>20$ & 140 & 40.35 \\
\hline
\end{tabular}

$\mathrm{N}=347$

\section{Impacts on Leadership}

The impacts of company size on leadership functions, skills, traits, and style are shown in Table 5.

Table 5. Impacts of Company Size on Leadership

\begin{tabular}{|c|c|c|c|c|}
\hline \multirow{2}{*}{$\begin{array}{l}\text { Dependent Variables } \\
\text { Functions }\end{array}$} & \multicolumn{4}{|c|}{$\begin{array}{c}\text { Independent Variable } \\
\text { Company Size }\end{array}$} \\
\hline & Coef & SE Coef & T-Value & P-Value \\
\hline Shared Vision & 0.0220 & 0.0395 & 0.56 & 0.578 \\
\hline Meet Budgets & 0.0406 & 0.0353 & 1.15 & 0.250 \\
\hline Quality & -0.0021 & 0.0317 & -0.06 & 0.948 \\
\hline Productivity & 0.0426 & 0.0344 & 1.24 & 0.216 \\
\hline Innovation & 0.0073 & 0.0405 & 0.18 & 0.857 \\
\hline Profit & 0.1161 & 0.0386 & 3.01 & $0.003 *$ \\
\hline People & -0.0440 & 0.0355 & -1.24 & 0.216 \\
\hline Teamwork & -0.0312 & 0.0367 & -0.85 & 0.396 \\
\hline Suppliers & 0.1218 & 0.0427 & 2.85 & $0.005 *$ \\
\hline Empower & -0.1112 & 0.0414 & -2.68 & $0.008 *$ \\
\hline Compt. Adv. & -0.0191 & 0.0323 & -0.59 & 0.554 \\
\hline \multirow[t]{2}{*}{ Change Agent } & -0.0596 & 0.0405 & -1.47 & 0.142 \\
\hline & \multicolumn{4}{|c|}{ Company Size } \\
\hline Skills & Coef & SE Coef & T-Value & P-Value \\
\hline Technical & 0.0172 & 0.0396 & 0.43 & 0.664 \\
\hline Admin. & -0.0449 & 0.0368 & -1.22 & 0.223 \\
\hline Analytical & -0.0321 & 0.0328 & -0.98 & 0.329 \\
\hline Interpersonal & -0.1381 & 0.0328 & -4.21 & $0.000 *$ \\
\hline Communications & -0.0941 & 0.0285 & -3.30 & $0.001 *$ \\
\hline \multirow{2}{*}{ Planning } & 0.0051 & 0.0368 & 0.14 & 0.889 \\
\hline & \multicolumn{4}{|c|}{ Company Size } \\
\hline Traits & Coef & SE Coef & T-Value & P-Value \\
\hline Decisive & -0.0150 & 0.0348 & -0.43 & 0.666 \\
\hline Take Risk & -0.0967 & 0.0390 & -2.48 & $0.014 *$ \\
\hline Persistent & -0.1065 & 0.0371 & -2.87 & $0.004 *$ \\
\hline Confidence & -0.0918 & 0.0320 & -2.87 & $0.004 *$ \\
\hline Adaptable & -0.0317 & 0.0320 & -0.99 & 0.323 \\
\hline Sociable & -0.1178 & 0.0369 & -3.19 & $0.002 *$ \\
\hline \multirow[t]{2}{*}{ Open Minded } & -0.1058 & 0.0387 & -2.74 & $0.006^{*}$ \\
\hline & \multicolumn{4}{|c|}{ Company Size } \\
\hline Style & Coef & SE Coef & T-Value & P-Value \\
\hline Participatory & -0.265 & 0.104 & 0.104 & $0.011 *$ \\
\hline Task Oriented & -0.045 & 0.095 & 0.095 & 0.634 \\
\hline Emp. Oriented & -0.205 & 0.100 & 0.100 & $0.042 *$ \\
\hline
\end{tabular}

The statistically significant negative effects of company size on empowering followers coupled with negative but not significant effects on obtaining people with needed skills and fostering teamwork suggest that increasing company size reduces the importance of employee engagement and leader-follower interactions. This is further suggested by 
the statistically significant positive effects of company size on ensuring profit goals are met and developing effective supplier relationships, and the positive but not statistically significant effects on ensuring budgets are met and improving productivity. The importance of leaders' financial functions increases while the importance of engaging employees and interacting with followers declines with increasing company size.

Consistent with the impacts of company size on leadership functions, increasing size reduces the importance of leadership skills essential to effectively engaging employees and interacting with followers. The statistically significant negative effects of company size on both interpersonal and communications skills are consistent with the declining importance of empowering followers, fostering teamwork, and obtaining people with needed skills. The statistically significant positive effects on the leader's technical and strategic planning skills also suggest engaging employees and leader-follower relationships are of lesser importance at larger organizations.

Company size has negative effects on all seven leadership traits. The statistically significant negative effect of increasing company size on sociability is consistent with the reduced importance of employee engagement and leader-follower interactions. The statistically significant negative effects on taking risks, and negative but not significant effects on being adaptable, open minded, persistent, confident, and decisive coupled with the reduced functional importance of being a change agent also strongly suggest that larger companies are more risk averse. The greater aversion to risks at larger organizations impacts leadership through its effects on the organization's structure, business and decision-making systems, policies, practices, and culture.

Increasing company size also has significant effects on leadership styles. Increasing size has statistically significant negative effects on both participatory and employee-oriented leadership styles; a significant positive effect on directive leadership; and a positive but not statistically significant effect on task-oriented leadership. These impacts again suggest that engaging employees and leader-follower interactions are less important at larger organizations.

The effects of company size on each component of the participatory and employee-oriented leadership constructs (company size has a negative but not statistically significant effect on task-oriented leadership) are shown in Table 6. The negative effects on all components of both participatory and employee-oriented leadership underscore the declining importance of employee engagement and leader-follower interactions at larger organizations. Increasing company size has negative effects on all three components of participatory leadership - a statistically significant negative effect on inviting followers to participate in decision making, and negative effects on encouraging followers to make suggestions for improvements and consulting with followers when facing a problem. Company size also has negative effects on all three components of employee-oriented leadership - a statistically significant negative effect on getting to know followers individually, and negative effects on showing concern for follower's job satisfaction, and encouraging followers to work together.

Table 6. Impacts of Company Size on the Components of Participatory and Employee-Oriented Leadership

\begin{tabular}{lcccc}
\hline Participatory & \multicolumn{4}{c}{ Company Size } \\
\cline { 2 - 5 } & Coef & SE Coef & T-Value & P-Value \\
\hline Decision Making & -0.0825 & 0.0408 & -2.02 & $0.440^{*}$ \\
Encourage & -0.0339 & 0.0384 & -0.88 & 0.378 \\
Consult & -0.0672 & 0.0389 & -1.73 & 0.085 \\
& & & & \\
\hline Emp. Oriented & & & & \\
\hline Know Followers & -0.1121 & 0.0398 & -2.81 & $0.005^{*}$ \\
Concern & -0.0633 & 0.0373 & -1.70 & 0.090 \\
Work Together & 0.0296 & 0.0382 & 0.77 & 0.439 \\
\hline
\end{tabular}

\section{Impacts on Leadership Effectiveness}

As shown in Table 7, company size has a positive but not statistically significant effect on leadership effectiveness despite its significant negative effects on the importance of numerous leadership functions, skills, traits, and styles. Thus, while leadership functions, skills, traits, and styles are significantly different at larger companies, leaders at larger organizations are not seen as more or less effective. Leaders at larger organizations perform the functions essential to these organizations as effectively as leaders at smaller organizations perform the functions essential to their organizations. 
Table 7. Impacts of Company Size on Leadership Effectiveness

\begin{tabular}{lcccc}
\hline & \multicolumn{4}{c}{ Company Size } \\
\hline \multirow{2}{*}{ Effectiveness } & Coef & SE Coef & T-Value & P-Value \\
\cline { 2 - 5 } & 0.0034 & 0.0348 & 0.0348 & 0.922 \\
\hline
\end{tabular}

\section{Discussion}

The numerous impacts of company size on leadership functions, skills, traits, and style evidence patterns of employee engagement and leader-follower interaction at larger companies that are significantly different from smaller companies. The significant negative effects of company size on participatory and employee-oriented leadership and positive effect on directive leadership, coupled with negative effects on empowering followers, promoting teamwork, interpersonal and communications skills, and on being sociable and open minded make a compelling argument that increasing company size reduces the importance of leaders engaging and interacting with followers.

The declining importance of engagement and leader-follower interactions as company size increases likely reflects characteristics of larger organizations, including more rigid hierarchical structures, formal policies and procedures, larger spans of control, standardized operating and decision-making systems, specialized personnel and other staffs, legal constraints and societal expectations, and restrictive cultures that lessen the importance of or substitute for employee engagement, interpersonal interactions (Stodgill \& Scott, 1957), and leadership (Kerr \& Jermier, 1978; Daft, 2011; duBrin, 2013).

The leader's role at larger organizations is significantly different than at smaller organizations, but the leadership is not viewed as more or less effective. This suggests leadership effectiveness depends more on alignment with the organization's strategy, policies, practices, procedures, and culture than on any particular leadership skill, trait, or style.

The study also found that larger companies are more risk averse. The statistically significant negative impacts of company size on empowering employees, and the negative but not significant impacts on being a change agent; the significant negative effects on taking risks, being persistent, confident, and open minded; and the increasing importance of directive leadership and greater relative importance of task-oriented leadership with increasing company size all suggest more cautious, conservative risk-taking behavior at larger companies. The larger organization's greater aversion to risk taking affects leadership through its impacts on the organization's structures, systems, policies, and procedures that delimit the leader's roles, responsibilities, decision-making scope, authority, and discretion. The greater aversion to taking risks at larger organizations reflects in part the greater difficulty of monitoring and controlling the actions of larger organizations, the magnitude of potential losses, and the likelihood that the large size of the company, measured as total sales revenue, reflects past success that also breeds conservatism. "Challenging the status quo," may not be as fashionable at large successful organizations as "don't rock the boat."

\section{Conclusions}

Explicating the relationships between size and leadership helps practitioners better define essential leadership functions, roles, and responsibilities for their organizations, and better prepare future leaders for these specific functions, roles, and responsibilities. Practitioners need to develop leadership training and development programs that provide their leaders with leadership skills, traits, and styles that are in synch with their organization. Alignment, not a particular leadership skill, trait or style, is the key to effective leadership.

There are also a number of implications for teaching leadership, where the current emphasis is on the importance of interpersonal skills (communicating, motivating, inspiring, empowering, and encouraging followers) captured in the notions that you "manage things and lead people," and "what got you here won't keep you here." While interpersonal skills are essential to effective leadership at any organization, their importance to future leaders at large organizations may be overstated relative to other critical leadership skills at these organizations. For example, Andrews (1971) viewed the leader as the chief architect of the organization's strategy, and Montgomery charged that all leaders "... must accept and own strategy as the heart of their responsibilities" $(2012$, p. 13). This suggests leadership classes may want to place more emphasis on the importance of the leader's technical and strategic planning skills and responsibilities (Marx, 2013).

Classroom distinctions between leaders and managers (e.g., leaders challenge the status quo, managers maintain the 
status quo; leaders empower people, managers control people; and leaders lead people, managers manage things) may again overstate the importance of interpersonal skills relative to technical, planning and other leadership skills at large organizations where classroom distinctions between leaders and managers may not be as dramatic.

\section{Future Research}

The findings in this paper have numerous implications for future research. Future research exploring the specific characteristics of larger companies, including hierarchical structures, spans of control, business systems, formalized procedures, specialized staffs, risk adversity, and organizational culture that may lessen the importance of engaging employees and leader-follower interactions should be high on the future research agenda for leadership. Statistically, future studies need to determine the specific characteristics of larger companies that mediate the impacts of company size on leadership. Future studies could profitably explore how the external environment, competitive intensity, growth, regulation, and other external factors, moderate the impacts of company size on leadership. They could also explore the relationships between the economic concept of diminishing marginal returns to scale, broadly attributed to a declining ability to manage larger companies effectively, and the impacts of company size on leadership found in this study.

Authentic, servant, empathic, credible, ethical, and transformational leadership that account for much of the current research in leadership are all rooted in quintessential employee engagement and leader-follower interactions. It would thus be valuable to explore the practice, importance, and effectiveness of these leadership styles at organizations of different size.

\section{References}

Andrews, K. R (1971). The concept of corporate strategy. Homewood, IL: Dow Jones-Irwin.

Bass, B. M. (1960). Leadership, psychology, and organizational behavior. New York, NY: Harper.

Bass, B. M. (2008). The bass handbook of leadership: Theory, research, \& managerial applications $\left(4^{\text {th }} \mathrm{ed}.\right)$. New York, NY: The Free Press.

Blake, R. R., \& Mouton, J. S. (1964). The managerial grid. Houston, TX: Gulf.

Blankenship, L. V., \& Miles, R. E. (1968). Organizational structure and managerial decision behavior. Administrative Science Quarterly, 13, 106-120. https://doi.org/10.2307/2391263

Bowers, D. G., \& Seashore, S. E. (1966). Predicting organizational effectiveness with a four factor theory of leadership. Administrative Science Quarterly, 11, 238-63. https://doi.org/10.2307/2391247

Cicchetti, D. V., \& Sparrow, S. S. (1990). Assessments of adaptive behavior in young children. In J.J. Johnson, \& J. Goldman (Eds.), Developmental assessment in clinical child psychology: A handbook. 173-196. New York: Pergamon Press.

Cronbach, L. (1951). Coefficient alpha and the internal structure of tests. Psychometrika, 16, 297-334. https://doi.org/10.1007/BF02310555

Daft, R. L. (2011). The leadership experience ( $5^{\text {th }}$ ed.). Mason, OH: South-Western.

DuBrin, A. J. (2013). Leadership ( $7^{\text {th }}$ ed.). Mason, OH: South Western.

Erez, M., \& Rim, Y. (1982). The relationships between goals, influence, tactics, and personal and organizational values. Human Relations, 35, 871-878. https://doi.org/10.1177/001872678203501004

Fiedler, F. E. (1967). A theory of leadership effectiveness. New York, NY: McGraw-Hill.

Hemphill, J. K., \& Coons, A. E. (1957). Development of the leader behavior description questionnaire. In R. Stodgill, \& A. Coons (Eds.), Leader behavior: Its description and measurement. Columbus, OH: Ohio State University, Bureau of Business Research.

Hersey, P., \& Blanchard, K. H. (1969). Life cycle theory of leadership. Training \& Development Journal, 23, 26-34.

Hersey, P., \& Blanchard, K. H. (1977). Management of organizational behavior: Utilizing human resources. Englewood Cliffs, NJ: Prentice Hall.

House, R.J. (1996). Path-goal theory of leadership: Lessons, legacy, and a reformulated theory. Leadership Quarterly, 7, 323-352. https://doi.org/10.1016/S1048-9843(96)90024-7 
Hughes, R.L., Ginnett, R.C., \& Curphy, G.J. (2009). Leadership: Enhancing the lessons of experience (6 ${ }^{\text {th }}$ ed.). New York, NY: McGraw Hill-Irwin.

Kerr, J. L. (1985). Diversification strategies and managerial rewards: An empirical study. Academy of Management Journal, 28, 155-179. https://doi.org/10.2307/256066

Kerr, S., \& Jermier, J. M. (1978). Substitutes for leadership: Their meaning and measurement. Organizational Behavior and Human Performance, 22, 375-403. https://doi.org/10.1016/0030-5073(78)90023-5

Kirkpatrick, S. A., \& Locke, E. A. (1991). Leadership: Do traits matter? The Executive, 5, 48-60. https://doi.org/10.5465/AME.1991.4274679

Korman, A. K. (1966). Consideration, initiating structure, and organizational criteria. Personal Psychology, 18, 349-360. https://doi.org/10.1111/j.1744-6570.1966.tb00310.x

Kotter, J.P. (1990). What leaders really do. In On leadership. Boston, MA: Harvard Business Review Press.

Kouzes, J. M., \& Posner, B. Z. (2007). The leadership challenge. San Francisco, CA: Jossey-Bass.

Marx, T. G. (2013). Teaching leadership and strategy. Business Education Innovation Journal, 5(3), 12-19.

Marx, T. G. (2015). The impact of business strategy on leadership. Journal of Strategy and Management, 8(2), 110-126. https://doi.org/10.1108/JSMA-06-2014-0042

Miner, J. B. (1982). The uncertain future of the leadership concept: Revisions and clarifications. Journal of Applied Behavioral Science, 18, 293-307. https://doi.org/10.1177/002188638201800305

Montgomery, C. A. (2012). The strategist. New York, NY: HarperCollins.

Munford, M.D., Zaccaro, S.J., Connelly, M.S, \& Marks, M.A. (2000). Leadership skills: Conclusions and future directions. Leadership Quarterly, 11(1), 155-170. https://doi.org/10.1016/S1048-9843(99)00047-8

Northouse, P. G. (2014). Leadership: Theory and practice ( $6^{\text {th }}$ ed.). Los Angeles: Sage.

Sheridan, J. E., \& Vredenburgh, D. J. (1979). Structural model of leadership influence in a hospital organization. Academy of Management Journal, 27, 57-78. https://doi.org/10.2307/255957

Stodgill, R. M., \& Scott, E. L. (1957). Responsibility and authority relationships. In R. M. Stodgill (Ed.), Leadership and structures of personal interaction. Columbus, OH: Ohio State University, Bureau of Business Research.

Tannenbaum. R., \& Schmidt, W. H. (1958). How to choose a leadership pattern. Harvard Business Review, 36(2), 95-101.

Vienneau, J. (1982). A study of leadership behavior of volunteer administrators in amateur sports organizations in the province of New Brunswick, Canada. Dissertation Abstracts International, 43(9B), 2931.

Vroom, V.H., \& Yetton, P.W. (1974). Leadership and decision making. Pittsburgh, PA: University of Pittsburgh Press.

Wofford, J. C. (1971). Managerial behavior, situational factors, and productivity and morale. Administrative Science Quarterly, 16, 10-17. https://doi.org/10.2307/2391281

Yukl, G. (2006). Leadership in organizations, (6 ${ }^{\text {th }}$ ed.). Upper Saddle River, NJ: Pearson-Prentice Hall.

Zaccaro, S. J. ((2007). Trait-based perspectives on leadership. American Psychologist, 62, 6-16. https://doi.org/10.1037/0003-066X.62.1.6 